\title{
Avaliação de nove linhagens de milho em cruzamentos dialélicos quanto à tolerância ao alumínio(1)
}

\author{
Geraldo Magela de Almeida Cançado(2), Sidney Netto Parentoni(3), Aluízio Borém ${ }^{(4)}$ \\ e Maurício Antônio Lopes ${ }^{(5)}$
}

\begin{abstract}
Resumo - Avaliaram-se nove linhagens endogâmicas de milho e seus cruzamentos quanto à tolerância ao alumínio (Al), em um dialelo incompleto. Foram utilizados os índices fenotípicos de comprimento relativo de raiz seminal (CRRS), comprimento líquido de raiz seminal (CLRS) e coloração por hematoxilina, determinados após sete dias de crescimento em solução nutritiva contendo $222 \mu$ moles L-1 de Al. Os resultados dos cruzamentos dialélicos demonstraram que os efeitos aditivos foram mais importantes que os efeitos não-aditivos para os três índices avaliados. As linhagens L13, L724, L723 e L16 seriam as mais indicadas para a obtenção de híbridos visando tolerância ao Al, por apresentarem os melhores valores de capacidade geral de combinação e por participarem dos cruzamentos de melhor capacidade específica de combinação. Uma correlação de 0,76 foi observada entre os índices CLRS e a coloração por hematoxilina, de 0,63 entre CLRS e CRRS e de 0,27 entre CRRS e coloração por hematoxilina. A coloração por hematoxilina demonstrou ser uma valiosa ferramenta para programas de melhoramento de milho que visam a seleção de genótipos com maior tolerância ao alumínio.
\end{abstract}

Termos para indexação: progênie, solução nutritiva, pigmentos, comprimento da raiz, melhoramento vegetal.

\section{Evaluation of nine maize inbred lines in diallel cross in relation to aluminum tolerance}

\begin{abstract}
Nine maize inbred lines and their hybrid combinations were evaluated in incomplete diallel crosses to study the aluminum (Al) tolerance behavior. The phenotypic indexes used to determine $\mathrm{Al}$ tolerance were the relative seminal-root length (RSRL), the net seminal-root length (NSRL) and the hemathoxylin staining, determined after seven days of growth in nutrient solution with $222 \mu$ moles $L^{-1}$ of Al. The diallel crosses results showed that additive effects were more important than not additive effects, for all indexes evaluated. Maize lines L13, L724, L723, and L16 showed better behaviour for general combining ability (GCA) and specific combining ability (SCA) and are the more indicated for obtaining Al-tolerant hybrids. The correlation observed between NSRL and hematoxylin staining was 0.76 , between NSRL and RSRL was 0.63 and between RSRL and hematoxylin staining equal to 0.27 . Therefore, hematoxylin appears to be a suitable tool to assist Al-tolerance selection in maize breeding programs.
\end{abstract}

Index terms: progeny, nutrient solution, pigments, root length, plant breeding.

(1) Aceito para publicação em 17 de julho de 2001

(2) Empresa de Pesquisa Agropecuária de Minas Gerais, Fazenda Experimental de Caldas, Caixa Postal 33, CEP 37780-000 Caldas, MG. E-mail: cancado@epamigcaldas.gov.br

(3) Embrapa-Centro Nacional de Pesquisa de Milho e Sorgo, Caixa Postal 151, CEP 35701-970 Sete Lagoas, MG E-mail: sidney@cnpms.embrapa.br

(4) Universidade Federal de Viçosa, Dep. de Fitotecnia, CEP 36570-000 Viçosa, MG. E-mail: borem@mail.ufv.br

(5) Embrapa-Sede, CEP 70770-901 Brasília, DF E-mail: mauricio.lopes@embrapa.br

\section{Introdução}

A toxidez do alumínio (Al) é o fator mais limitante à produtividade agrícola em solos ácidos (Kochian, 1995), que cobrem uma área de 1,66 milhões de hectares distribuídos em várias regiões do mundo, e aproximadamente $43 \%$ destas áreas estão localizadas na região tropical (Pandey et al., 1994). No Brasil, os solos ácidos encontram-se principalmente na região do Cerrado, ocupando cerca de 204 milhões de hectares do território nacional (Embrapa, 2000). 
Nos solos de $\mathrm{pH}$ levemente ácidos ou neutros, o Al está primariamente na forma de óxidos ou aluminossilicatos, mas, quando os solos se tornam mais ácidos, formas fitotóxicas de Al são liberadas na solução do solo em níveis que afetam o crescimento da raiz e conseqüentemente da planta (Kinraide, 1991). Raízes de plantas cultivadas na presença de níveis tóxicos de $\mathrm{Al}$ tornam-se curtas, grossas, e não apresentam desenvolvimento de raízes laterais, aumentando a suscetibilidade à seca e reduzindo a absorção dos nutrientes da solução do solo (Bona et al., 1991). No caso da cultura do milho, a maioria das cultivares comerciais é suscetível ao $\mathrm{Al}$, mas existe variabilidade genética dentro desta espécie quanto à tolerância ao alumínio. Dessa forma, uma alternativa adequada para aumentar a eficiência desta cultura no Cerrado é o desenvolvimento de cultivares mais bem adaptadas a solos com níveis tóxicos de $\mathrm{Al}$ (Howeler, 1991). Para a maioria das espécies de plantas, a característica de tolerância ao $\mathrm{Al}$ é dominante, podendo ser controlada por um ou mais genes de ação maior, que atuam juntamente com genes modificadores (Kochian, 1995). Há uma grande variação nos relatos sobre herança da tolerância ao $\mathrm{Al} \mathrm{em} \mathrm{milho,} \mathrm{com} \mathrm{resultados} \mathrm{descrevendo} \mathrm{desde}$ herança monogênica (Rhue et al., 1978; Garcia Júnior \& Silva, 1979), passando por característica controlada por dois genes complementares dominantes (Miranda et al., 1984), até herança poligênica (Magnavaca, 1982; Sawazaki \& Furlani, 1987; Lima et al., 1992; Torres et al., 1997).

Existem várias formas de identificação de genótipos padrões quanto à tolerância e quanto à suscetibilidade ao alumínio. A resposta de cultivares de uma mesma espécie de planta à toxidez de $\mathrm{Al}$ tem sido avaliada no campo, em vasos em casa de vegetação e em experimentos com solução nutritiva (Fageria et al., 1988). Entre estes, a utilização de solução nutritiva contendo Al permite avaliar a capacidade de tolerância ao $\mathrm{Al}$ em um grande número de plantas de maneira rápida, simples e econômica. O uso de solução nutritiva permite, ainda, um melhor domínio de fatores que na maioria das vezes são de difícil controle e mensuração no solo, que podem interferir, tanto no comportamento das plantas, quanto na ação tóxica do Al (Magnavaca, 1982). No entanto, apesar de suas vantagens, a solução nutritiva deve ser empregada para discriminar os genótipos mais tolerantes e sensíveis em um estágio preliminar do programa de melhoramento, reduzindo o número de genótipos que posteriormente deverão ser avaliados em solos ácidos, que apresentam, além da toxidez causada pelo $\mathrm{Al}$, outros fatores estressantes para a planta. Isto permite uma significativa redução no uso de área e no custo das avaliações (Magnavaca \& Bahia-Filho, 1991).

O índice mais simples utilizado para separar cultivares tolerantes e sensíveis tem sido dividir a produção no nível sem estresse pela produção obtida no nível com estresse. Este índice tem sido amplamente utilizado (Sangalang \& Bouwkamp, 1988) e visa separar efeitos variáveis de potencial produtivo entre as diversas cultivares, da resposta ao estresse de cada cultivar individualmente. Um sério limitante ao uso desse índice é que ele tende a favorecer cultivares não-responsivas a ambientes com ausência de estresse, podendo subestimar o comportamento de genótipos superiores.

Índices que se baseiam na redução do crescimento radicular de plantas cultivadas em solução nutritiva contendo $\mathrm{Al}$, tais como o crescimento relativo de raiz seminal (CRRS) e o crescimento líquido de raiz seminal (CLRS), têm sido freqüentemente utilizados na identificação de genótipos de milho tolerantes ao $\mathrm{Al}$ (Magnavaca, 1982). Outra forma muito utilizada para avaliar o crescimento radicular consiste na determinação da taxa de redução do crescimento radicular de plantas cultivadas na presença do $\mathrm{Al}$, em relação a plantas cultivadas na ausência desse elemento (Furlani \& Clark, 1987). Embora os métodos acima sejam adequados, a técnica de coloração das raízes com hematoxilina, corante que possui a propriedade de se complexar com cátions livres, temse mostrado eficiente para discriminar genótipos de milho tolerantes ao $\mathrm{Al}$, de forma precoce e nãodestrutiva (Cançado et al., 1999). O método é simples e baseia-se na propriedade colorimétrica da hematoxilina, que origina uma coloração azul-púrpura no tecido radicular, quando na presença do Al. Em trigo, a intensidade de coloração por hematoxilina em ápices radiculares é inversamente proporcional à tolerância dos genótipos ao $\mathrm{Al}$ (Polle et al., 1978). Dessa forma, genótipos tolerantes e sensíveis podem ser identificados com o uso de 
hematoxilina antes que diferenças no crescimento das raízes sejam mensuráveis (Delhaize et al., 1993).

Além da necessidade de um marcador fenotípico eficiente, outra dificuldade encontrada pelo melhorista é o grande número de genótipos a serem avaliados. A escolha dos genótipos mais promissores para serem utilizados como progenitores em programas de cruzamento permite que a maioria dos esforços seja dedicada àquelas populações segregantes potencialmente capazes de fornecer progênies superiores, traduzindo-se em maior eficiência do programa de melhoramento. A técnica de cruzamentos dialélicos assume grande importância nesta questão, pois auxilia o melhorista na escolha de progenitores com base nos seus valores genéticos e, principalmente, considerando a sua capacidade de se combinarem em híbridos promissores (Ramalho et al., 1993; Cruz \& Regazzi, 1997).

O presente estudo teve como objetivo estimar a capacidade geral de combinação (CGC) e a capacidade específica de combinação (CEC), quanto à tolerância do milho ao Al, em um dialelo incompleto.

\section{Material e Métodos}

Utilizaram-se nove linhagens endogâmicas de milho (L11, L13, L16, L20, L22, L36, L64, L723 e L724) e seus respectivos cruzamentos $F_{1}$, obtidos em um dialelo incompleto, realizado no ano de 1997. As linhagens de milho são originadas do programa de desenvolvimento de híbridos de milho para solos ácidos da Embrapa-Centro Nacional de Pesquisa de Milho e Sorgo (CNPMS), Sete Lagoas, MG iniciado na década de 70 a partir de avaliação em solos ácidos e férteis de um grupo de mais de 2.000 linhagens $\mathrm{S}_{2}$, derivadas de 6.200 plantas $\mathrm{S}_{1}$ (Bahia Filho et al., 1978) e fazem parte do acervo do programa de melhoramento de milho para tolerância a solos ácidos. As linhagens L13, L16, L723 e L724 possuem tolerância média para $\mathrm{Al}$ em solução nutritiva, enquanto L11, L20, L22, L64 e L36 possuem tolerância baixa para Al em solução nutritiva.

As sementes de milho foram tratadas com $0,1 \%(\mathrm{p} / \mathrm{p})$ do fungicida Captan 750 TS e colocadas para germinar em rolos de papel (Germilab) umedecidos em água destilada. Após seis dias, selecionaram-se as plântulas com germinação uniforme e sem danos visíveis nas raízes, as quais foram transferidas para bandejas contendo $8,5 \mathrm{~L}$ de solução nutritiva com a seguinte composição em $\mu$ moles $\mathrm{L}^{-1}$ :

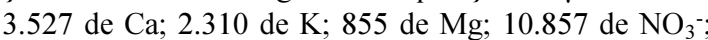

1.300 de $\mathrm{NH}_{4}^{+} ; 45$ de $\mathrm{P} ; 587$ de S; 25 de B; 595 de Cl; 77 de Fe; 9,1 de $\mathrm{Mn} ; 0,63$ de $\mathrm{Cu}$; 0,83 de Mo; 2,29 de Zn; 1,74 de Na; e 75 de EDTA, como descrito em Magnavaca (1982). O Al foi fornecido na forma de $\mathrm{KAl}\left(\mathrm{SO}_{4}\right)_{2} \cdot 12 \mathrm{H}_{2} \mathrm{O}$, na concentração final de $222 \mu$ moles $\mathrm{L}^{-1}$. O experimento foi realizado em câmara de crescimento regulada para 14 horas de luz, com intensidade luminosa de $340 \mu \mathrm{mol} \mathrm{m}^{-2} \mathrm{sec}^{-1}, 30^{\circ} \mathrm{C}$, e umidade relativa de $70 \%$ e 10 horas de escuro; $21^{\circ} \mathrm{C}$ e umidade relativa de $90 \%$. As plântulas de milho foram fixadas em suportes de plástico apoiados sobre as bandejas contendo solução nutritiva. Cada suporte era formado por sete colunas de sete orifícios, totalizando 49 plântulas por bandeja. $\mathrm{O}$ pH da solução nutritiva foi ajustado para 4,2 , sendo monitorado e corrigido diariamente.

O comprimento da raiz seminal das plântulas $(\mathrm{cm})$ foi medido momentos antes da transferência para as bandejas, para determinação do comprimento inicial da raiz seminal (CIRS), e sete dias após, para determinação do comprimento final da raiz seminal (CFRS). O crescimento líquido da raiz seminal (CLRS) foi obtido pela diferença entre o CFRS e CIRS, e o crescimento relativo da raiz seminal (CRRS) foi obtido pela divisão do CLRS pelo CIRS (Magnavaca, 1982). A coloração por hematoxilina foi realizada logo após a determinação do CFRS. As plântulas de cada parcela foram agrupadas em conjuntos devidamente identificados, e cerca de 30 conjuntos tiveram suas raízes cuidadosamente acondicionadas em bandejas de plástico de $8 \mathrm{~L}$, contendo água destilada em volume suficiente para cobrir totalmente as raízes, e foram agitadas suavemente por 15 minutos. Em seguida, trocou-se a água destilada por igual volume de solução de hematoxilina ( $2 \%$ de hematoxilina MERCK e $0,2 \%$ de iodeto de potássio, p/v), agitando-se por 20 minutos. Por fim, trocou-se novamente a solução por água destilada, agitando-se por mais 15 minutos. Os ápices radiculares das plântulas foram classificados visualmente por quatro avaliadores independentes, e as notas foram conferidas seguindo uma escala de pontos que variava de 0 a 5 , em que ápices radiculares com ausência completa de coloração recebiam nota 0 , e ápices completamente corados recebiam nota 5 . No estudo da capacidade combinatória das linhagens dos cruzamentos dialélicos, foram utilizadas as médias dos valores de CRRS, CLRS e coloração por hematoxilina, obedecendo ao método 2 de análise combinatória proposto por Griffing (1956), cujo modelo matemático é:

$\mathrm{Y}_{\mathrm{ij}}=\mathrm{m}+\mathrm{g}_{\mathrm{i}}+\mathrm{g}_{\mathrm{j}}+\mathrm{s}_{\mathrm{ij}}+\mathrm{e}_{\mathrm{ij}}$

onde: $\mathrm{Y}_{\mathrm{ij}}$, é o valor médio do híbrido $(\mathrm{i} \neq \mathrm{j})$ ou do progenitor $(i=j) ; m$, a média geral; $g_{i}, g_{j}$, os efeitos da capacidade geral de combinação do i-ésimo e do j-ésimo progenitor, 
respectivamente; $\mathrm{s}_{\mathrm{ij}}$, o efeito da capacidade específica de combinação do cruzamento entre os progenitores de ordem i e j; $e_{i j}$, o erro experimental médio; e i, j =1,2,..,9. Neste dialelo, foi considerado que $\mathrm{s}_{\mathrm{ij}}=\mathrm{s}_{\mathrm{ji}}$.

Desta forma, foram estimados os efeitos de CGC e CEC. O dialelo foi incompleto, devido à ausência dos híbridos L11xL36, L13xL64 e L36xL724, e o delineamento experimental empregado foi o de blocos casualizados, com 42 tratamentos e três repetições. Cada parcela foi constituída por sete plântulas, dispostas em uma coluna na bandeja de solução nutritiva, e as análises estatísticas dos dados de CRRS, CLRS e coloração por hematoxilina foram feitas com o auxílio do programa MSTAT-C versão 1.41 (Michigan State University).

\section{Resultados e Discussão}

Os efeitos da CEC, estimados como desvios do comportamento em relação ao que seria esperado com base na CGC, são medidas dos efeitos gênicos não-aditivos, tais como efeitos de dominância e epistasia. Normalmente, interessam ao melhorista as combinações híbridas com estimativas de CEC mais favoráveis e que envolvam pelo menos um dos progenitores com elevada CGC para o caráter. Entre as nove linhagens de milho utilizadas como progenitores neste estudo, os maiores valores de CGC relativos a CLRS foram obtidos para L $724(0,9297)$ e L13 $(0,7628)$, enquanto L36 $(-0,9702)$, L1 $1(-0,5416)$ apresentaram os menores valores (Tabela 1). Para CRRS, os progenitores L724 $(0,0551)$, L723 $(0,0384)$ e L13 $(0,0365)$ apresentaram os maiores valores de CRRS, enquanto os menores foram encontrados nas linha-

Tabela 1. Estimativas da capacidade geral de combinação de nove linhagens de milho para os índices de comprimento líquido da raiz seminal (CLRS), comprimento relativo da raiz seminal (CRRS) e coloração por hematoxilina. Embrapa-CNPMS, Sete Lagoas, MG. 1997.

\begin{tabular}{lrrr}
\hline Linhagem & CLRS & CRRS & Hematoxilina \\
\hline L11 & $-0,5416$ & $-0,0614$ & $-0,1798$ \\
L13 & 0,7628 & 0,0365 & $-0,4237$ \\
L16 & 0,2880 & $-0,0129$ & $-0,2821$ \\
L20 & $-0,2751$ & $-0,0177$ & 0,2211 \\
L22 & $-0,6080$ & $-0,0297$ & 0,0604 \\
L36 & $-0,9702$ & $-0,0276$ & 0,5759 \\
L64 & $-0,4323$ & 0,0186 & 0,1242 \\
L723 & 0,1774 & 0,0384 & 0,0848 \\
L724 & 0,9297 & 0,0551 & $-0,1263$ \\
\hline
\end{tabular}

Pesq. agropec. bras., Brasília, v. 37, n. 4, p. 471-478, abr. 2002 gens L11 (-0,0614), L22 (-0,0297) e L36 (-0,0276). Já para a coloração por hematoxilina, cujos valores negativos de CGC representam progenitores que conferem maior tolerância ao $\mathrm{Al}$, os maiores valores foram dos progenitores L13 $(-0,4237)$ e L16 $(-0,2821)$, enquanto L36 $(0,5759)$ e L20 $(0,2211)$ apresentaram valores indesejáveis.

Quanto maior a magnitude dos valores da CEC, melhor é a combinação híbrida, pois indica desvios de dominância favoráveis. Desta forma, os melhores valores de CEC, obtidos de forma geral com relação aos três índices avaliados, foram obtidos nos cruzamentos entre as linhagens L13xL16, L13xL20, L13xL723, L16xL22, L16xL723, L16xL724, L723xL22, L723xL64, L723xL11, L11xL22 e L11xL20 (Tabela 2).

Nos índices que apresentaram tanto a CGC como a CEC significativas, há a indicação de que os efeitos aditivos e os não-aditivos dos genes são importantes no controle genético desses caracteres, sendo, portanto, possível escolher progenitores e combinações híbridas mais promissoras, para aumentar a expressão desses caracteres. Neste trabalho, pela magnitude dos quadrados médios, os efeitos aditivos foram mais importantes que os efeitos não-aditivos, e na coloração por hematoxilina e em CLRS, o valor da CGC foi mais de quatro vezes superior ao valor da CEC, enquanto em CRRS o valor da CGC foi superior a duas vezes o valor da CEC. Nos índices de CRRS e de coloração por hematoxilina, efeitos não-aditivos ou desvios do modelo não apresentaram significância estatística, enquanto CLRS apresentou ambos os efeitos significativos (Tabela 3). Quanto aos efeitos de CGC significativos, podemos interpretar o resultado como um indicativo de que os progenitores apresentam diferenças em suas capacidades gerais de combinação quanto aos índices estudados, e que, também, a ação gênica aditiva é importante na expressão dos caracteres avaliados. Já para os efeitos de CEC significativos, há indicação de que os híbridos estudados mostram-se heterogêneos, na medida em que não apresentam o comportamento esperado com base na capacidade geral de combinação de seus respectivos progenitores, bem como, que a ação gênica não-aditiva foi importante na manifestação dos caracteres nos híbridos em teste. 
Tabela 2. Estimativas da capacidade específica de combinação em híbridos de nove linhagens de milho para os índices de comprimento líquido da raiz seminal (CLRS), comprimento relativo da raiz seminal (CRRS) e coloração por hematoxilina. Embrapa-CNPMS, Sete Lagoas, MG, 1997.

\begin{tabular}{lrrr}
\hline Cruzamentos & CLRS & CRRS & Hematoxilina \\
\hline L11 x L13 & 0,1294 & $-0,0205$ & $-0,3398$ \\
L11 x L16 & $-0,3191$ & 0,0044 & 0,0365 \\
L11 x L20 & 0,6239 & 0,0292 & $-0,1988$ \\
L11 x L22 & 0,5997 & 0,0338 & $-0,0560$ \\
L11 x L64 & $-0,1255$ & $-0,0396$ & 0,2373 \\
L11 x L723 & 0,5748 & 0,0341 & $-0,1518$ \\
L11 x L724 & 0,3958 & $-0,0186$ & $-0,5747$ \\
L13 x L16 & 1,2098 & 0,0459 & $-0,8357$ \\
L13 x L20 & 2,1495 & 0,0534 & $-1,1782$ \\
L13 x L22 & $-0,6581$ & $-0,0336$ & $-0,0175$ \\
L13 x L36 & $-0,5887$ & $-0,0034$ & 0,3197 \\
L13 x L723 & 0,5104 & 0,2163 & $-0,0597$ \\
L13 x L724 & 0,9714 & 0,0081 & 0,3031 \\
L16 x L20 & $-0,6357$ & $-0,0219$ & 0,0731 \\
L16 x L22 & 0,7201 & 0,0695 & $-0,1859$ \\
L16 x L36 & 0,2728 & $-0,0100$ & 0,0666 \\
L16 x L64 & $-0,4284$ & $-0,0594$ & $-0,0265$ \\
L16 x L723 & 0,4619 & 0,0555 & $-0,3977$ \\
L16 x L724 & 1,8762 & 0,0595 & 0,4010 \\
L20 x L22 & 0,2364 & $-0,0110$ & 0,0966 \\
L20 x L36 & 0,2692 & $-0,0442$ & 0,0544 \\
L20 x L64 & 0,3246 & $-0,0314$ & $-0,2529$ \\
L20 x L723 & $-0,1918$ & 0,0071 & 0,2776 \\
L20 x L724 & $-0,5841$ & 0,0948 & 0,1851 \\
L22 x L36 & $-0,2351$ & $-0,0416$ & $-0,2581$ \\
L22 x L64 & 0,5170 & 0,0019 & $-0,5118$ \\
L22 x L723 & 1,2873 & 0,0336 & $-0,2849$ \\
L22 x L724 & $-0,3250$ & 0,0615 & 0,2565 \\
L36 x L64 & 0,4964 & 0,2142 & 0,3254 \\
L36 x L723 & 0,3834 & 0,0075 & 0,0747 \\
L64 x L723 & 0,2522 & 0,0031 & $-0,4201$ \\
L64 x L724 & $-0,1401$ & $-0,0094$ & 0,1391 \\
L723 x L724 & 0,1035 & $-0,0994$ & $-0,0982$ \\
\hline
\end{tabular}

Tabela 3. Análise de variância para os índices de comprimento relativo da raiz seminal (CRRS), comprimento líquido da raiz seminal (CLRS), e coloração por hematoxilina de cruzamentos dialélicos de nove linhagens de milho. Embrapa-CNPMS, Sete Lagoas, MG, 1997.

\begin{tabular}{lrccc}
\hline Fonte de variação & GL & \multicolumn{3}{c}{ Quadrado médio } \\
\cline { 3 - 5 } & & \multicolumn{1}{c}{ CRRS } & CLRS & Hematoxilina \\
\hline Blocos & 2 & $0,00700^{\mathrm{ns}}$ & $0,4770^{\mathrm{ns}}$ & $1,7310^{* *}$ \\
Tratamentos & 41 & $0,00785^{\mathrm{ns}}$ & $1,5242^{* *}$ & $0,3485^{*}$ \\
$\quad$ Modelo (CGC) & 8 & $0,01518^{*}$ & $3,9120^{* *}$ & $0,9262^{*}$ \\
Desvios (CEC) & 33 & $0,00608^{\mathrm{ns}}$ & $0,9453^{* *}$ & $0,2085^{\mathrm{ns}}$ \\
Erro & 82 & 0,00600 & 0,4235 & 0,2135 \\
\hline CV (\%) & & 30,48 & 16,97 & 12,66 \\
Média geral & & 0,2436 & 3,8361 & 3,6843 \\
\hline
\end{tabular}

ns Não-significativo. ${ }^{*}$ e ${ }^{* *}$ Significativo a $5 \%$ e a $1 \%$ de probabilidade, respectivamente, pelo teste $\mathrm{F}$.
Nos índices de CRRS, CLRS e coloração por hematoxilina, as linhagens L13, L724, L723 e L16 seriam as mais indicadas para obtenção de híbridos visando à tolerância ao $\mathrm{Al}$, por apresentarem os melhores valores de CGC, enquanto as linhagens L36, L20 deveriam ser evitadas. É interessante ressaltar que entre os genótipos disponíveis no programa de melhoramento de milho para solos ácidos da Embrapa-CNPMS, as linhagens endogâmicas utilizadas neste estudo não são consideradas padrões extremos de tolerância ao $\mathrm{Al}$, pois possuem tolerância variando de média a baixa quanto à toxidez de $\mathrm{Al}$ em solução nutritiva. Entretanto, possuem alta capacidade combinatória em solo sob estresse de $\mathrm{P}$, e algumas delas produzem híbridos superiores em solo com média saturação de $\mathrm{Al}$ (Parentoni et al., 1996b). Desta forma, o uso destas linhagens em cruzamentos dialélicos é desejável, pois tem por objetivo produzir híbridos com melhor desempenho para as condições de solos de Cerrado, onde a baixa disponibilidade de $\mathrm{P}$ é considerada, conjuntamente com a presença de Al, forte limitante ao desenvolvimento das plantas.

Parentoni et al. (1996a), avaliando um dialelo em que algumas das linhagens utilizadas neste trabalho participaram, observaram, em solo com saturação de Al de 36\% (nível médio), que os valores das estimativas de CGC foram cerca de três vezes superiores aos de CEC, indicando, assim, que efeitos aditivos foram mais importantes para a produção de espigas. Esses mesmos autores, considerando o índice CRRS, utilizando solução nutritiva contendo $\mathrm{Al}$, observaram, ainda, que os valores de CGC foram mais de dez vezes superiores aos valores de CEC, novamente, indicando a importância de efeitos aditivos para a tolerância ao alumínio. Neste caso, as linhagens mais tolerantes foram L13 e L64, enquanto L723 foi intermediária, e L36 e L11 foram as mais sensíveis. Como os resultados representam os desempenhos relativos das linhagens em cruzamentos dialélicos específicos, comparações entre o comportamento dessas mesmas linhagens com resultados obtidos de dialelos de constituição diferente, em que elas tomaram parte, não é indicado. No entanto, espera-se que, para uma determinada linhagem, haja um comportamento coerente entre o resultado de dialelos em que ela tenha participado, quando se avaliam as mesmas 
características. Desta forma, os resultados obtidos neste trabalho reforçam os resultados obtidos, no que se refere às mesmas linhagens, no trabalho de Parentoni et al. (1996a).

O comportamento per se das linhagens utilizadas nos cruzamentos dialélicos, ou seja, o comportamento intrínseco das linhagens, não demonstrou valores elevados em relação à tolerância ao $\mathrm{Al}$ nos três índices avaliados (Tabela 4). A linhagem L36, apesar de ter apresentado bom desempenho em relação às outras linhagens, nos três índices avaliados não integrou nenhum cruzamento híbrido de valor elevado de CEC. No caso de culturas alógamas, o comportamento de híbridos em estudos envolvendo estresses, como toxidez por Al, é superior ao comportamento das linhagens per se, pois híbridos, em geral, apresentam maior vigor e tendem a produzir maior sistema radicular que suas linhagens progenitoras; além disso, as linhagens apresentaram alta variabilidade entre e dentro de parcelas experimentais, elevando o coeficiente de variação e dificultando a detecção de diferença entre tratamentos (Tabela 3).

Quanto à correlação existente entre as médias dos três índices, o melhor resultado $(0,76)$ foi observado entre o CLRS e a coloração por hematoxilina, seguido pela correlação entre CRRS e CLRS $(0,63)$. Apesar de o coeficiente de correlação entre CRRS e a coloração por hematoxilina ter sido baixo $(0,27)$, muito desse comportamento provavelmente deve ser explicado pelo elevado coeficiente de variação encontrado para o CRRS (Tabela 3). A falta de homogeneidade dentro de alguns tratamentos diante de problemas de vigor da semente pode ter influen-

Tabela 4. Desempenho per se das nove linhagens de milho para os índices de crescimento líquido da raiz seminal (CLRS), crescimento relativo da raiz seminal (CRRS), e coloração por hematoxilina. Embrapa-CNPMS, Sete Lagoas, MG, 1997.

\begin{tabular}{lccc}
\hline Linhagens & CLRS $(\mathrm{cm})$ & CRRS $(\mathrm{cm})$ & Hematoxilina \\
\hline L11 & 1,81 & 0,11 & 3,85 \\
L13 & 3,50 & 0,18 & 3,74 \\
L16 & 2,83 & 0,15 & 3,96 \\
L20 & 2,19 & 0,17 & 4,60 \\
L22 & 2,64 & 0,13 & 4,29 \\
L36 & 1,60 & 0,13 & 4,54 \\
L64 & 2,52 & 0,24 & 4,19 \\
L723 & 2,50 & 0,19 & 4,83 \\
L724 & 4,55 & 0,31 & 3,53 \\
\hline
\end{tabular}

Pesq. agropec. bras., Brasília, v. 37, n. 4, p. 471-478, abr. 2002 ciado negativamente os resultados do CRRS, em maior intensidade do que para CLRS e para coloração por hematoxilina. Esta falta de homogeneidade também foi responsável pela perda de três tratamentos do dialelo (L11xL36, L13xL64 e L36xL724) os quais foram excluídos, por não apresentarem número suficiente de plântulas homogêneas para comporem o dialelo.

\section{Conclusões}

1. Tanto os efeitos gênicos aditivos como nãoaditivos são importantes na manifestação dos caracteres estudados, sendo os efeitos aditivos, proporcionalmente, mais acentuados do que os nãoaditivos.

2. Os resultados de CGC e CEC sugerem que as linhagens de milho L13, L724, L723 e L16 possam ser utilizadas como progenitores superiores para formação de híbridos com maior tolerância ao alumínio.

3. Os resultados de CGC e CEC revelam que as linhagens de milho L36 e L20 deveriam ser evitadas para formação de híbridos com maior tolerância ao alumínio.

4. O teste de coloração por hematoxilina, usado conjuntamente com os testes de CRRS e CLRS, pode discriminar genótipos de milho quanto à tolerância ao $\mathrm{Al}$, de forma eficaz e precoce.

\section{Agradecimentos}

Ao Programa de Apoio a Núcleos de Excelência (PRONEX), INCO project - Comunidade Européia, Fundação de Amparo à Pesquisa do Estado de Minas Gerais (Fapemig), e ao Conselho Nacional de Desenvolvimento Científico e Tecnológico (CNPq).

\section{Referências}

BAHIA FILHO, A. F. C.; FRANÇA, G. E.; PITTA, G. V. E.; MAGNAVACA, R.; MENDES, J. F.; BAHIA, F. G. F. T.; PEREIRA, P. Avaliação de linhagens e populações de milho em condições de elevada acidez. In: REUNIÃO BRASILEIRA DE MILHO E SORGO, 11., 1976, Piracicaba. Anais... Piracicaba: Esalq, 1978. p. 51-58.

BONA, L.; MATUZ, J.; PURNHAUSER, L. Aluminium tolerance of Triticum aestivum L. populations related to 
plant-induced $\mathrm{pH}$ changes of nutrient solution. In: WRIGHT, R. J.; BALIGAR, V. C.; MUMMANN, R. P. (Ed.). Plant-soil interactions at low pH. Dordrecht: Kluwer Academic, 1991. p. 1057-1062.

CANÇADO, G. M. A.; LOGUERCIO, L. L.; MARTINS, P. R.; PARENTONI, S. N.; BORÉM, A.; PAIVA, E.; LOPES, M. A. Hematoxylin staining as a phenotypic index for aluminum tolerance selection in tropical maize (Zea mays L.). Theoretical and Applied Genetics, Berlin, v. 99, p. 747-754, 1999.

CRUZ, C. D.; REGAZZI, A. J. Modelos biométricos aplicados ao melhoramento genético. 2. ed. Viçosa: UFV, 1997. $390 \mathrm{p}$.

DELHAIZE, E.; RYAN, P. R.; RANDALL, P. J. Aluminum tolerance in wheat (Triticum aestivum L.). II: aluminum-stimulated excretion of malic acid from root apices. Plant Physiology, Rockville, v. 103, p. 695-702, 1993.

EMBRAPA. Centro de Pesquisa Agropecuária dos Cerrados (Planaltina, DF). Ecossistema: o cerrado brasileiro. Disponível em: http://www.cpac.embrapa.br/unidade.htm Acesso em: 23 set. 2000.

FAGERIAN. K.; WRIGHT, R. J.; BALIGAR, V. C. Rice cultivar evaluation for phosphorus use efficiency. Plant and Soil, Dordrecht, v. 111, p. 105-109, 1988.

FURLANI, P. R.; CLARK, R. B. Plant traits for evaluation of responses of sorghum genotypes to aluminium. In: GABELMAN, H. W.; LOUGHMAN, B. C. (Ed.). Genetic aspects of plant mineral nutrition. Dordrecht: Kluwer, 1987. p. $247-254$.

GARCIA JÚNIOR, O.; SILVA, W. J. Análise genética da tolerância ao alumínio em milho. Ciência e Cultura, São Paulo, v. 31, p. 585, 1979.

GRIFFING, B. Concept of general and specific combining ability in relation to diallel-crossing systems. Australian Journal of Biological Sciences, Collingwood, v. 9, p. 463-493, 1956.

HOWELER, R. H. Identifying plants adaptable to low pH conditions. In: WRIGHT, R. J.; BALIGAR, V. C.; MUMMANN, R. P. (Ed.). Plant-soil interactions at low pH. Dordrecht: Kluwer Academic, 1991. p. 885-904.

KINRAIDE, T. B. Identity of the rhizotoxic aluminum species. Plant and Soil, Dordrecht, v. 134, p. 167-178, 1991.
KOCHIAN, L. V. Cellular mechanisms of aluminum resistance in plants. Annual Review of Plant Physiology, Palo Alto, v. 46, p. 237-260, 1995.

LIMA, M.; FURLANI, P. R.; MIRANDA FILHO, J. B. Divergent selection for aluminum tolerance in a maize (Zea mays L.) population. Maydica, Bergamo, v. 37, p. 123132, 1992.

MAGNAVACA, R. Genetic variability and the inheritance of aluminum tolerance in maize ( $\mathrm{Zea}$ mays L.). 1982. 135 f. Tese (Ph.D.) - University of Nebraska, Lincoln. 1982.

MAGNAVACA, R.; BAHIA FILHO, A. F. C. Seleção de milho para tolerância ao alumínio. Sete Lagoas: Embrapa-CNPMS, 1991. 30 p. Apostila.

MIRANDA, L. T.; FURLANI, P. R.; MIRANDA, L. E. C.; SAWAZAKI, E. Genetic of environmental resistance and super-genes latent aluminum tolerance. Maize Genetics Cooperation Newsletter, Missouri, v. 58, p 46-48, 1984.

PANDEY, S.; CEBALHOS, H.; GRANADOS, G.; KNAPP, E. Developing maize that tolerates aluminum toxic soils. In: EDMEADES, G. E.; DEUTSCH, J. A. (Ed.). Stress tolerance breeding: maize that resist insects, drought, low nitrogen and acidic soils. México: Centro Internacional de Mejoramiento de Maíz y Trigo, 1994. 344 p.

PARENTONI, S. N.; BAHIA-FILHO, A. F. C.; GAMA, E. E. G.; LOPES, M. A.; GUIMARÃES, P. E. O.; SANTOS, M. X. Capacidade combinatória de linhagens elite de milho em solo ácido e fértil. In: REUNIÓN LATINOAMERICANA, 3.; REUNIÓN DE LA ZONA ANDINA E DE INVESTIGADORES EN MAÍZ, 16. 1996, Cochabamba. Memoria... México: Cimmyt, 1996a. p. 35-46.

PARENTONI, S. N.; GAMA, E. E.; LOPES, M. A.; SANTOS, M. X.; OLIVEIRA, P. E.; ELEUTÉRIO, A.; BAHIA FILHO, A. F. C.; ALVES, V. M. C.; COELHO, A. M.; PAIVA, E.; VASCONCELOS, M. J. V. P. Avanços no programa de adaptação de milho a solos ácidos do CNPMS/ EMBRAPA. In: REUNIÓN DE COORDINADORES SURAMERICANOS DE PROGRAMAS DE MAÍZ, 4., 1996, Cali. Memoria... México: Cimmyt, 1996b. p. 74-103. 
POLLE, E.; KONZAK, C. F.; KITTRICK, J. A. Visual detection of aluminum tolerance levels in wheat by hematoxylin staining of seedling roots. Crop Science, Madison, v. 18, p. 823-827, 1978.

RAMALHO, M. A. P.; SANTOS, J. B.; ZIMMERMANN, M. J. Genética quantitativa em plantas autógamas: aplicações ao melhoramento do feijoeiro. Goiânia: Editora da UFG, 1993. $271 \mathrm{p}$.

RHUE, R. D.; GROGAN, C. O.; STOCKMEYER, E. W.; EVERETT, H. L. Genetic control of aluminum tolerance in corn. Crop Science, Madison, v. 18, p. 1063-1067, 1978.
SANGALANG, J. B.; BOUWKAMP, J. C. Selection of sweet potato for tolerance to aluminum toxicity: screening procedures and field test. Journal of the American Society for Horticultural Science, Alexandria, v. 113, p. 277-281, 1988.

SAWAZAKI, E.; FURLANI, P. R. Genética da tolerância ao alumínio em linhagens de milho cateto. Bragantia, Campinas, v. 46, p. 269-278, 1987.

TORRES, G. A.; PARENTONI, S. N.; LOPES, M. A.; PAIVA, E. A search for RFLP markers to identify genes for aluminum tolerance in maize. Brazilian Journal of Genetics, Ribeirão Preto, v. 20, p. 459-465, 1997. 